\title{
'Unheard Voices of Van Gujjar Women': A Thematic Analysis of Coping Patterns by Women in the Context of Sedentarization among Himalayan Pastoralists
}

\author{
Rubina Nusrat \\ Department of Social Work, Jamia Millia Islamia University, India
}

Copyright $(2015$ by authors, all rights reserved. Authors agree that this article remains permanently open access under the terms of the Creative Commons Attribution License 4.0 International License

\begin{abstract}
The Van Gujjars families migrating to the Alpine pastures today face the same fate of being the 'victims of conservation'. It started in the forest of foothills at the beginning of the 1990s with Rajaji National Park, but during the last decade most of the summer pastureland in the upper ranges has also been converted into national parks, global heritage sites or sanctuaries. Apart from National parks, Van Gujjars elsewhere had the right to graze their animals in parts of the forest against a fixed grazing fee. But now some forests are being closed by the implementation of Joint Forest Management Programmes. This Paper is based on a mixed research in which the quantitative aspect aimed at identifying the factors and levels of women empowerment before and after sedentarization through a Women empowerment Index. Qualitative research aimed to explore perspectives of young women from Gujjar community in terms of patterns of coping in their sedentarized life. Narratives of women presented a sense of collectivism and identification with issues and concerns of other Gujjars in terms of an identity of victimhood and a sense of being marginalized and socially excluded. Following patterns of coping emerged from narratives: Use of existing resources, Women as Livestock owners and managers, Women as Leaders in Migration, Work Participation and status of women, Women as Builders of Asset base, Gujjar womenthe Natural resource managers, Coping through normalizing and acceptance, Coping in social matters and Assurance for moneylenders.
\end{abstract}

Keywords Van Gujjar, Women Empowerment, Sedentarization, Coping Patterns

\section{Introduction}

Van Gujjars are fully pastoralists following transhumance between two distinct eco zones without much diversification of subsistence strategy. The passageways between different subsistence strategies often encounter a regular thoroughfare. Guha [1] in his study on scientific forestry emphasizes that in Himalayas, comparable conflict developed as colonial governments appropriated forests from local communities to promote scientific forestry. Similarly, Maikhuri et al [2] Proposed that the creation of National parks and protected areas has led to the removal of local inhabitants and/or their exclusion from traditionally used natural resources.

The problems faced by Van Gujjars due to marginalization and exclusion

The Muslim Gujjars of Uttaranchal are not included in the list of other backward classes. This implies that the development of the nomadic Gujjars in Uttaranchal has been the sole responsibility of the forest department which has wanted to restrict the grazing of the Gujjar buffaloes in the forests of the area. The marginalization of Van Gujjars got enhanced with the creation of new state of Uttarakhand in 2000, creating one more border right through the winter camps of Van Gujjars in the Shivalik foothills. So a Van Gujjar residing in the foothills of Shivaliks of Uttar Pradesh need to migrate to the Alpine regions of Uttarakhand or Himachal Pradesh need to migrate through Uttarakhand where they are seen as intruders with no permanent State belonging, as gets evident in the case of Van Gujjars of Uttar Pradesh who were stopped from migrating to their summer pastures in Uttarkashi in the State of Uttarakhand. The marginalization of Van Gujjars started when the strict systems of control for pastoralists were introduced by the British government. These controls enforced that most flexible variables at the disposal of pastoralists in order to migrate were time for migration and routes and now these variables were to be decided by State officials rather than the herders themselves. The controls further emphasized on the restrictions on herd size with the limited number of animals they were allowed to keep despite being fully pastoralists. These rules left the Van Gujjars waiting every summer in the lowlands for the checkpoints to be established along the migratory routes and for official permission to proceed up 
into the hills. This further took away the right of migration at the right time from Van Gujjars, indirectly pushing them towards sedentarization. The biggest factor that contributes to their marginalization is the lack of Civil Rights i.e. they have no access to domicile rights, policy advocacy, Lobbying and education. There is non existence of linkages between them and government services for education, health and veterinary support. This emphasizes on the exclusion faced due to shrinkage of pastures owing to the creation of National parks in their traditional pasture land, traditional view of conservation by forest authorities as being anti people and negative attitude of villagers on the migratory routes.

\section{An Overview about Sedentarization}

In a study by Nusrat R [3], it is stated that the critical conflict between pastoralism and conservation in Uttarakhand started in early 1980s after establishment of two national parks in the vital summer grazing zones of pastoral livestock in Chamoli district in 1982 following Wildlife (Protection) Act, 1972. Creation of Rajaji National Park spreading over $820.42 \mathrm{~km}^{2}$ in foothill forests of three districts (Dehradun, Haridwar and Pauri) in 1983 led to bring to an end of pastoral livelihood of Van Gujjars. Gooch [4] emphasizes that in order to survive as pastoralists and in order to use the land in a sustainable way, the Van Gujjars thus have to maintain access to a landscape that allows them to be flexible. However, the opportunities for nomadic pastoralism along the altitudes are rapidly decreasing and many options for flexibility are now either severely curtailed or completely lost. According to government, the sedentarization was needed for improvement of the forest dwelling Van Gujjars and conserving the wildlife diversity especially of Asiatic Elephant in the region. Some of the families have been settled by the government at two colonies of Pathri and Gaindikhatta near Haridwar in Uttarakhand. Plantation forests were cleared to create the Pathri colony at the cost Rs. 3 crore. The colony consisted of 512 two roomed tenements-dark and dingy, with little ventilation. Surrounded by marshy lands near the river Ganga on one side, a railway track and fields of the zamindars (landlords) on the other, living conditions at Pathri were unbearable. The Gujjars saw it as Kaalapaani (sentenced for life). The Van Gujjar population in the Rajaji National Park is given below:

Table 1. The Van Gujjar population in the Rajaji National Park (1985-1998)

\begin{tabular}{|c|c|c|c|}
\hline S.No & Forest range & $\begin{array}{c}\text { No. of } \\
\text { families } \\
(\mathbf{1 9 8 5})\end{array}$ & $\begin{array}{c}\text { No. of } \\
\text { families } \\
(\mathbf{1 9 9 8})\end{array}$ \\
\hline 1. & Haridwar & 85 & 254 \\
\hline 2. & Chilla & 181 & 193 \\
\hline 3. & Motichur & 37 & 116 \\
\hline 4. & Kansrao & 11 & 85 \\
\hline 5. & Chillawali & 65 & 260 \\
\hline 6. & Dholkhand & 116 & 234 \\
\hline 7. & Ramgarh & 17 & 99 \\
\hline 8. & Gohri & - & 149 \\
\hline & $\begin{array}{c}\text { Total families that were to } \\
\text { be rehabilitated }\end{array}$ & $\mathbf{5 1 2}$ & $\mathbf{1 3 9 0}$ \\
\hline
\end{tabular}

Source: Joshi,2009

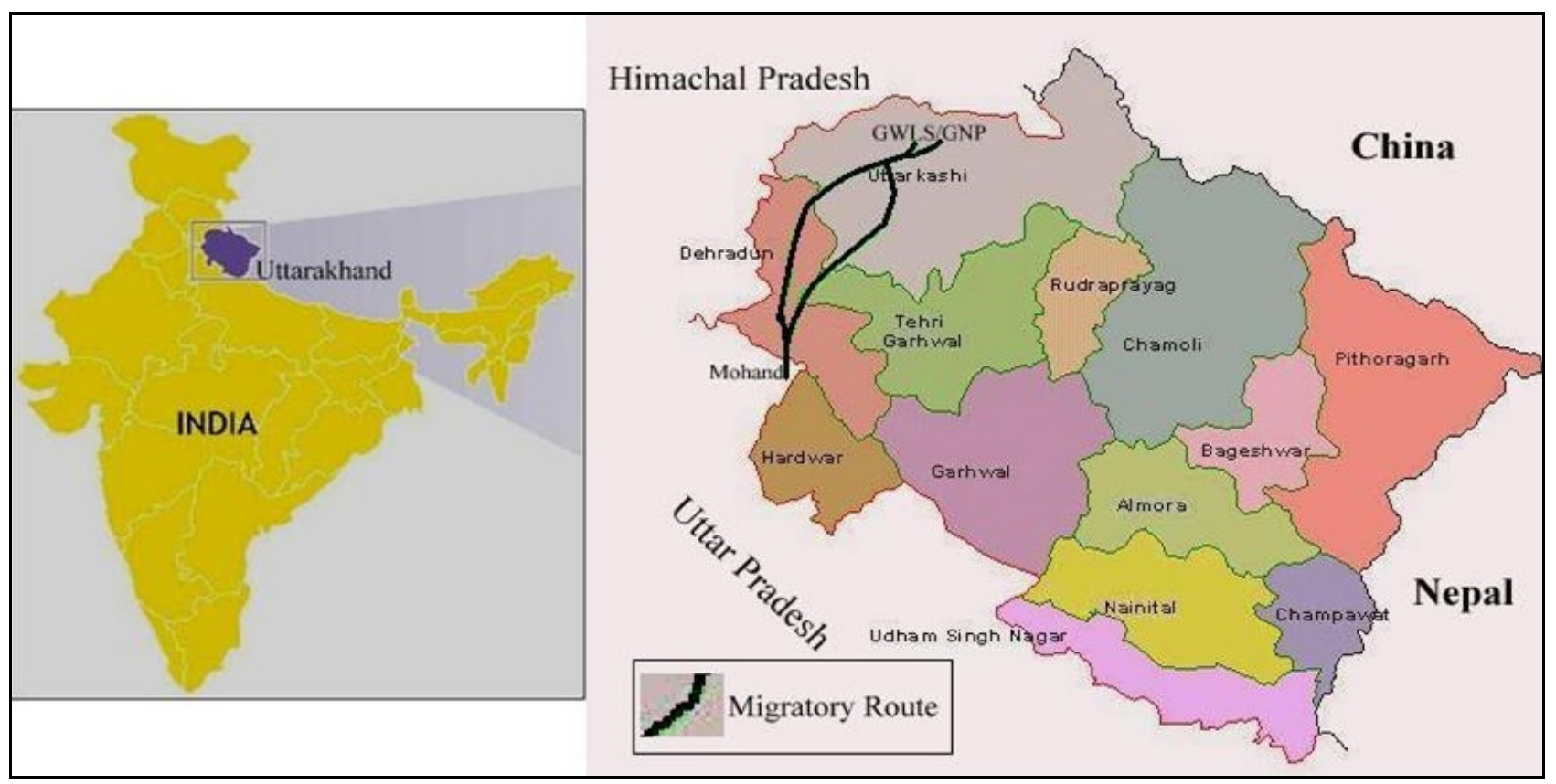

Figure 1. Map showing migratory route of Van Gujjars from Siwalik foothill forest to Alpines 


\section{Study Area}

The winter camps of the Van Gujjars is in the Shivalik forest division which lies west of the Delhi - Dehradun highway and outside the Rajaji National Park, lying between $20025^{\prime} \mathrm{N}$ and $30025^{\prime} \mathrm{N}$ Latitude and $72035^{\prime} \mathrm{E}$ to $78015^{\prime} \mathrm{E}$ longitude, while the Rajaji National Park area lies in the east of the highway and includes Rajaji, Motichur and Chila lying between $29050^{\prime} \mathrm{N}$ to $30015^{\prime} \mathrm{N}$ latitude and $77055^{\prime} \mathrm{E}$ to 780 30 'E longitude. The summer pastures comprises of Govind National Park in Uttarkashi district covering an area of 472.08 sq.km was carved out from Govind Wildlife Sanctuary in 1990. The altitude of the park varies from $2056 \mathrm{~m}$ to $6323 \mathrm{~m}$ above msl. The alpine meadows occupy approximately one-fifth area of the park which is used as summer grazing land for more than 30 migratory shepherd groups

\section{The Study}

The objectives of this research aimed to answer the following three questions focusing on scenario of Sedentarization: What were the factors that led to empowerment of women before and after Sedentarization? What were the patterns in life of women, Gujjar community, which helped them cope and survive in the context of sedentarization? What were the similarities and differences in these patterns among women from men?

The study followed a mixed method approach. With emphasis on scenario of Sedentarization, Quantitative techniques of preparing a women empowerment index in order to assess the factors that led to increase or decrease of women empowerment before and after sedentarization. The qualitative aspect of this research focused on how women in Gujjar community cope with challenges associated with living in the context of sedentarization.

The Universe of the study was the shivalik foothills of Himalayas which lie in the states of Uttar Pradesh (Saharanpur) and Uttarakhand (Dehra dun) in India. The data was collected in November 2013 in the two districts of Dehradun and Saharanpur.

The sample size for the quantitative study was 70 women across a wide age range of women (25-60years) were included who have been adapting to the changing sedentarization through coping. The Qualitative study included 10 women in the age group of 18-70 years. Among these, 5 were from Dehradun District and 5 from the Saharanpur District. Out of 10 participants, 5 were older women with children (age ranging between 30-60) who stayed in Deras and were into livestock keeping whose families still practised transhumance, 3 were young unmarried girls whose families have become sedentarized, 1 was a pregnant women and 1 was a local dai.

For Quantitative analysis, an empowerment index was developed based on the deduced factors from secondary review of literature and letter of validation from experts in women studies. For example, in the variable of decision making, scores were assigned on the scale of 1 to 3 on the basis of who makes the decision, assigning the highest score when the decision was taken by female spouse alone. For each activity, the scores were then multiplied by the number of respondents under respective decision makers' category, which were then summed up and converted on the scale of 3 and were named as 'empowerment scores'. The empowerment index was then evolved by dividing the average empowerment scores for participant/non- participant for all activities by 3 . The deduced factors of empowerment were then qualitatively discussed based on the inputs from participant observation, FGD, case studies and narratives.

The qualitative sample comprised of women from different social, economic and educational backgrounds to understand multiple perspectives. Qualitative data collection was followed by transcription and translation of interviews and notes. This study also included few perspectives/narratives which, brought out the qualitative aspects of field well. These are being presented in the section on findings with specific focus on- description of sedentarization scenario and its impacts; and the way women coped with these impacts.

All interviews were conducted by the researcher in Hindi and Gujjari with the help of an interpreter. All the respondents were identified through local contacts who sought permission from them to participate in the research after informing them about the theme of this research. An interview guide was used in the process of data collection. Following themes were explored in the interview: factors that generally contribute to coping among women after sedentarization in the Gujjar community and coping strategies implied by Gujjar women. Before beginning any interview, about 20 minutes to half an hour was spent by the researcher in sharing about herself, the research, the content and process of the interview. The researcher also explained how confidentiality would be ensured in the research. Any questions that respondents had before or after the interview were answered by the researcher. Respondents had a choice to not answer questions if they felt uncomfortable.

In this study, the term Empowerment was referred a process of social and economic building leading to greater social participation, to greater decision-making and economic control among women of Gujjar community. Coping was understood in terms of strategies, tactics, responses, cognitions, or behaviors used to deal with the impacts of marginalisation and exclusion of Gujjar community.

\section{Limitations of the Study}

Since there is paucity of literature due to limited researches done on this community owing to their inaccessibility due to migration. The findings are completely based on the primary data collected through interviews and participant observation, henceforth, it lacks a comparison with earlier studies. As the sample size for qualitative aspects was small, it is likely that many perspectives have not been 
covered in this research. This limitation however is compensated by the use of in depth interviews.

It is also likely that most participants responded as 'spokespersons' for Gujjar community instead of focusing on their individual lives because the interview focused on the coping strategies of the sedentarization scenario. This, however, further strengths the finding- as it emerges through this paper- that Gujjar have a collective view of themselves and their situation.

\section{Findings}

\section{Factors Leading to Coping Patterns amongst Gujjar Women before and after Sedentarization}

Flintan [5] emphasizes in her study on women and pastoralism that indeed, not only is there difference in the socio-economic status of and constraints over pastoral women, but also there are differences between the pastoral systems themselves and level of mobility on which they are based; the systems of 'rights' available to both men and women including de jure, de facto, nominal and actual; and women's and men's own perceptions of what 'empowerment' means, just to name a few. The quantitative aspect of study illustrates that Van Gujjar women before sedentarization had least score in Decision making in use of Family Planning and Work Participation. The highest score was in Decision making in Migration and Decision making in Natural resource management. After sedentarization, the lowest score was in Decision making in use of Family Planning and Work Participation. The highest score was in Ownership of Livestock and Control own income.

The factor that had no change in empowerment scores before and after sedentarization was work participation. This showed that Van Gujjar women even after sedentarization, restricted themselves to livestock rearing and natural resource management like lopping and grazing, with no participation in formal work force. The change in empowerment score values before and after sedentarization was seen maximum in Decision making in the use of family planning as prior to sedentarization, Van Gujjar were aware of family planning methods but did not have access to it as they were on the move while migrating. Nusrat R [6] in her study brings forth a fact that the Van Gujjar women adapt to the changing situations by a strategy of the eldest women leading the herd on the migratory route in order to make negotiations with the forest officials. Further on, the women seems more willing and more adaptive to modern ways of family planning and they have shown a positive result during a project of Family planning launched by Government. Now with sedentarization, their access to family planning has increased due to a regular visit of an ANM in their Khols. However, the women whose husbands were reluctant on usage of family planning even if she willed, now she had the option of taking family planning from ANM in the absence of husband. The change in empowerment scores was observed least in Decision making in migration as the sedentarized Van Gujjar families have stopped migrating to the alpines, primarily owing to less number of livestock and secondary, after sedentarization, the engagement of Van Gujjar males in employment generation schemes like MGNREGS (Mahatma Gandhi National Rural employment generation scheme). The MGNREGS works are started during July- August during which time the migrating Van Gujjars are present in the alpines. So the non-migratory Van Gujjar restrained from going to alpines and sent their livestock along with the migratory Van Gujjars.

Table 2. Factors leading to coping patterns amongst Gujjar women before and after Sedentarization

\begin{tabular}{|c|c|c|c|c|c|c|c|}
\hline \multirow{2}{*}{ Independent Variable } & \multicolumn{3}{|c|}{ Empowerment Index Score } & \multicolumn{3}{c|}{ chi square Results } \\
\cline { 2 - 7 } & Before & After & Difference & $\chi^{2}$ & $\begin{array}{c}\text { Asymp sig } \\
\text { Dfsided) }\end{array}$ \\
\hline Work Participation & 1.88 & 1.88 & 0 & 35.37 & 2 & \multicolumn{3}{|c|}{ Dependent variable } \\
\hline Ownership of Livestock & 1.95 & 2.45 & +0.5 & 35.42 & 2 & $.000^{* *}$ \\
\hline Ownership of Other Assets & 1.95 & 2.42 & +0.47 & 51.65 & 2 & $.000^{* *}$ \\
\hline Control own income & 2 & 2.42 & +0.42 & 4.14 & 2 & $.042^{* *}$ \\
\hline $\begin{array}{c}\text { Decision making in Control Natural Resource } \\
\text { base }\end{array}$ & 2.07 & 2.27 & +0.2 & 14.21 & 2 & $.000^{* *}$ \\
\hline Decision making related to Social Matters & 1.95 & 2.27 & +0.32 & 3.48 & 2 & $.175 \mathrm{NS}$ \\
\hline Decision making in Family Planning & 1.27 & 1.87 & +0.6 & 14.21 & 2 & $.001^{* *}$ \\
\hline Decision making Financial Matter & 2.05 & 2.24 & +0.19 & 24.24 & 2 & $.000^{* *}$ \\
\hline Decision making in Migration & 2.07 & 2.24 & +0.17 & 26.09 & 2 & $.000^{* *}$ \\
\hline Access to credit & 1.95 & 2.22 & +0.27 & & & \\
\hline Overall Index value & 0.54 & 0.73 & +0.19 & & \\
\hline
\end{tabular}

*Significant at $5 \% * *$ Significant at $1 \%$ NS- Non significant 
Furthermore, as the impact of sedentarization was to be assessed on the empowerment levels of women, so chi square test has been used to see the level of association between empowerment of women and workforce participation taken as proxy variable for sedentarization. The Table 2 shows the Chi square association of Van Gujjar and Tongia women workforce participation and other variables of empowerment. Highly significant positive association at $1 \%$ level of significance was found between respondents' workforce participation and ownership of livestock, ownership of other assets, control over own income, Decision making in social matters, and access to credit, Decision making in migration. Significant but medium positive association at $1 \%$ level of significance was found between respondents workforce participation and control over natural resources. Non significant association at $1 \%$ level of significance was found between respondents' workforce participation and decision making in family planning.

The overall Index value of women empowerment before sedentarization was .54 and after sedentarization was .73 showing an improvement by 19 .

\section{Coping Patterns Implied by Gujjar Women in the Context of Vulnerability Related to Sedentarization}

\section{Use of Existing Resources of Family and Community}

Coping strategies tend to have negative effects on the asset base. Gujjar women resort to minimal Coping strategies in the inevitable circumstances. The first option available to the poor and the destitute Gujjar women is wild food, which is consumed only under crisis situation. The women, then desperately look for alternative coping strategies, such as social supports from their matrilocal relatives than food aid from external sources. For such vulnerable times, cutting of meal frequency from the current level puts them to a level of starvation and hence, considered not as better option. Hence, further cutting of meal frequencies then migration are taken as a last resort. On the other hand, the medium and rich categories of the society have the options of selling small ruminants, sell their cattle and to avoid starvation. The opportunities of asking for social support and food aid were indicated in the form of zakat ( financial aid from rich to poor). This makes the information given credible and reliable, as the communities were biased for seeking outside benefits.

Another coping strategy is to sell their breeded livestock on their migratory route in lieu of economic gains, forsaking one of their established rule of not selling their livestock in the foothills. In terms of the herd size and herd composition, there has been a considerable change as increased small ruminant cattle like goats and sheeps come handy as an instant cash as the changing lifestyle along with changing food habits have made it difficult to hold on to the money reserves at hand. Another coping strategy on their migratory routes is in the way overstaying at one place due to reduction in the number of parao ( halting places) and suffering themselves and livestock. The women are constantly on a move on the migratory routes due to which their health deteriorates. For Gujjar women, material culture is limited to a way of subsistence strategy. As Husan Bano, a Gujjar woman puts it, -Hum to aate- jate log hai (we are people always on a move). We need to be on a move so we limit our Household material keeping our migration as topmost thing in our mind. More of material means more of liability. We need to take care of Buffaloes, our children, our material possession and also our own selves so logically, we reduce on what we can reduce i.e. material possession.

\section{Women as Livestock Owners and Managers}

In Gujjars, livestock forms the core of the livelihood framework, henceforth, it gets imperative to understand the access and ownership of livestock along with livestock management and decision making processes among the Van Gujjar women. In the Gujjar community, women are given livestock as a part of dowry as a security of her future and also in placing her in a position of reverence in the husbands house. As Gujjar community is mainly affected by Islamic inheritance rules, some livestock go to the unmarried daughters on the death of the household head although they are managed by the brothers of the Gujjar women. At the time of marriage, husband gives livestock to his wife in mehr (Dower) so the majority of livestock is under the ownership of Gujjar women.

Although in Gujjar community, most of the times women are said to be "the hidden hands" of livestock production and a reservoir of indigenous knowledge, however, in Gujjar community, women have a role of livestock manager and owner and are bestowed with decision making powers concerning its sale and use. It is a general rule that the Van Gujjar women have a lot of say in the matters regarding livestock management and buying and selling of livestock. Field observations showed that it is the Gujjar woman who deals with diagnosis and the choice of treatment for sick livestock but its men and children who while grazing the buffaloes collect and prepare the concoctions used in traditional remedies. Most of the extension workers and people from NGOs are able to communicate directly with the womenfolk despite the Islamic (Muslim) custom of veil (purdah) owing to womenfolk knowing the most about the ethno veterinary. The reason cited by most of them is that little daughters always accompany her father at the time of milking of Buffaloes. Father milks the Buffalo while the girl child plays around with other Buffaloes. In this process, she gets trained in taking care of Buffaloes and their diagnosis since her childhood days. Zakeena, a Van Gujjar women emphasized," A buffalo will be reproductive till the time she is alive. Even when the Buffalo turns barren, she 
brings immense luck, and to have such a buffalo in your herd is a very good omen. We ensure that Buffaloes are taken care of until they die. She gave us milk, she is our mother. How can we kill our mother?"

\section{Women as Leaders in Migration}

After this, Decision making in Migration forms the next pertinent variable contributing to the empowerment of Van Gujjar women. The fact that it is the Gujjar women who lead the kafila (a number of migratory households) can be validated from this data. It is the older women of the family who take charge of the migration process. It is she who decides and ensures the timely departure of an early party of man-folk along with the fast moving Baas (herd of Buffaloes) and the second party of women and children along with the remaining household items follows them. The Oldest women leads the group carrying all the important documents along with her and it is she who makes all the relevant negotiations with the forest officials regarding the grazing fees and permit. This phenomenon gets reemphasized by the fact that every time one seeks for their grazing permits, the male of the family asks the female head to take it out from her safe custody. While crossing the forests, women folk deal with the forest guards and negotiates with them in terms of allowing them to cross the forests without any hindrance. Sain Bibi, the wife of Lamberdar (the head of clan), leads the caravan and emphasizes, "janglaat ke afsaro ko alag hi baat samajh me aati hai (forest officials understand a different language). If our menfolk try to negotiate then they are harassed by the forest guards so it is I who carry the important documents along with me to convince the officials."

Whenever the Caravan (migratory group) halts at some place, it is the women folk who take the central place not just in terms of setting of the Deras ( homesteads) but also of the stalking of Buffaloes so that they can be maximum fed. It gets evident when it is the men folk who at the time of migration moves along with the livestock the 'baas'(herd of Buffaloes) ahead of the whole Dera while it is the women folk who hold on to the grounds with the children and household material possession. Womenfolk pack the household material and moves along with the 'maal' (material possessions)later on. Womenfolk follow the kafila (a number of migratory households) throughout the transhumant trail on the same lines whereby the slow moving Buffaloes leave early from the respective halting places called 'paraos' along with the men folk and women and children follow them later on.

\section{Work Participation and Status of Women}

Gujjar male and female separate the spheres of action and responsibility related to livestock.

Table 3 enumerates the mean time spent by female is 18.24 hours and mainly in the tasks involving hard toil like cutting fodder, health care of animals and bringing animal feed on a daily basis. The maximum mean time spent by a Gujjar male is 15.63 hours which is mainly in the grazing of the Buffaloes while Gujjar women spend 18.24 hours in works of hard toil like the cutting of fodder and collection of feed for the Buffaloes including lopping emphasizing on the fact that women tend to the Buffaloes more in terms of physical labour and mean time spent by them in looking after the livestock. Accessing water is a key challenge for Gujjar women and is one of the greatest determinants of Gujjar woman's workload. In conditions of water shortage, women spend three hours each day collecting water, with negative consequences for their own health, income earning opportunities, household survival and child care. Gujjar women when in times of seasonal migration travel long distances moving along with livestock (often with the homestead) on a low energy diet and in heat. The intermittent halts are marked with additional duties of carrying heavy loads of water, fuelwood or fodder over long distances causing stress on the body. Van Gujjar women are a depiction of one of strongest breeds, both mentally and physically. When it was questioned to Van Gujjar women that what makes them strong to go with this kind of labour? One of Van Gujjar women, Husan Bano answered, "Gujjars have been a warrior tribe from the very start so our men were gone for days together. It was the women folk who were left behind to take care of home, children, livestock and sustenance of trees around their Deras. We got used to doing everything on our own. Even today, our men go for grazing of Buffaloes and selling of milk for the whole day and we are left behind to take care of home, children, livestock, trees and a newly added element of dealing with moneylenders. Now, we enjoy the central position we own in our household and work harder to retain it."

Table 3. One day Work Distribution Pattern between Gujjar male and Female

\begin{tabular}{|c|c|c|c|}
\hline $\begin{array}{c}\text { Work } \\
\text { Distribution }\end{array}$ & $\begin{array}{c}\text { Male (mean } \\
\text { no. of hours) }\end{array}$ & $\begin{array}{c}\text { Female (mean } \\
\text { no. of hours) }\end{array}$ & Difference \\
\hline Cutting Fodder & .46 & 4.53 & +4.07 \\
\hline $\begin{array}{c}\text { Prepare animal } \\
\text { feed }\end{array}$ & .13 & 1.86 & -.27 \\
\hline Grazing animal & 7.73 & .00 & -7.73 \\
\hline $\begin{array}{c}\text { Health care of } \\
\text { animals }\end{array}$ & .73 & 4.73 & +4.00 \\
\hline $\begin{array}{c}\text { Water animal } \\
\text { Bring water }\end{array}$ & 1.33 & 1.13 & -.20 \\
\hline Cleaning animal & 1.26 & 3.60 & +3.47 \\
\hline $\begin{array}{c}\text { Cleaning animal } \\
\text { shed }\end{array}$ & .13 & .13 & -1.13 \\
\hline Milking animals & 1.33 & 1.13 & +1.00 \\
\hline $\begin{array}{c}\text { Cleaning } \\
\text { Utensils }\end{array}$ & .00 & .00 & -1.33 \\
\hline $\begin{array}{c}\text { Selling milk } \\
\text { products }\end{array}$ & 2.40 & .00 & +1.13 \\
\hline Total & $\mathbf{1 5 . 6 3}$ & $\mathbf{1 8 . 2 4}$ & +2.40 \\
\hline
\end{tabular}

\section{Women as Builders of Asset Base}

Van Gujjar women have sole ownership of income received from sale of livestock products and they spend it at their own will. This showed that Van Gujjar women have 
complete discretion of either sharing her income with the family or spending it alone. Gujjar Women are typically responsible for milking and dairy processing; they may or may not sell the milk, and they usually have control over the proceeds in order to feed the family. Men are responsible for herding and selling milk products. A Gujjar woman deals with household social subsistence through her income additions in whatever little way she could through the selling of weaved out blankets or beaded necklaces. Her concern is to ensure that the needs of households members are satisfied from one day to another, from one season to another, from one location to the next. Due to their ambiguous nature, Gujjar women play a relevant role in constructing the social fabric, as they often belong to different clans (the one of the husband and that of the father), establish neighbourhood relationships and form associations and organizations - often informal - which are vital for local livelihoods. One of the enterprising Gujjar women Masab Bibi has made contributions in terms of her innovative enterprising is in terms of barter exchange patterns in the alpines which enriches the family household unit. Material possession gets enhanced through the exchange of woollen sheet called khais weaved out of old torn clothes by Gujjar woman. This khais is exchanged in lieu of Goondh, a horse back seat prepared by the local villagers. This Goondh forms an essential part of her household assets as it is majorly required in the transhumance process to carry the Household materials i.e maal. As Masab Bibi aptly puts it by saying, "what remains in hand is a pearl and what flows away from hand is water so why not we should try to retain the maximum relevant to us and for us."

\section{Gujjar Women- The Natural Resource Managers}

Van Gujjar women alone collect fuel wood, carry the drinking water from the water sources, lop the trees around the Deras and dry the grasses for the lean season while majority of women perform jointly the following activities with their husbands in grazing, lifting of heavy loads, construction of Deras, clearing of forests and by being the previous party during migration. This showed the high management potential of Van Gujjar women in sharing of household workload. Women's increased management and control of resources helps them gain confidence in decision making processes. Gujjar women during the dry season dig in the water holes nearby their Deras as the river dry up during summer season and other sources like waterholes shared by animals and human gets polluted to be used as drinking water. It is a rule set by the Gujjar women in the alpines and foothills as well that a person is allowed to defecate at least $2 \mathrm{kms}$ away from a river source and also of the Dera.

Kammo, wife of Feroz, is 45 years old female. She emphasizes that Gujjar women knows about 90 species of plants that can be used for both human and livestock, as fumigants and insecticides for rituals. The colic of the new born baby is treated with the concoction of a number of herbs along with buffalo milk. It is during the lopping, she takes her daughters along with her in the forests and they collect in this process, she keeps educating them over the nutritional aspects of the various leaves. While lopping, she also trains the young girls how to pluck the weeds along with leaves. She says, "Lopping is just about cutting the leaves without taking into consideration the branches but it is about cutting the leaves in such a way that there are greater prospects of the trees growing further. We take special care of a giant creeper 'maljan' that grows in the monsoon period while lopping as we understand the symbiotic relationship these creepers and trees share amongst themselves. We climb the trees and lop them so that the creeper remains intact." This shows that Gujjar women understand the intrinsic values of nature around them and reciprocate to them as towards the emotions of human beings.

In the Gujjar society, women's dependence on the natural resource base is inevitable for food, water, Dera building material, traditional medicine and animal fodder. Edgaonkar [7] emphasizes in his study that branches were lopped for fodder from many trees, drastically altering the forest canopy, affecting regeneration of trees and leading to a proliferation of weeds on the forest floor. Women bring within the Dera natural resources which are closer to the Dera while men folk collects the material from far into dense forest areas. It would be a Gujjar woman who would be seen with a bundle of dried twigs on her head to be used as fuelwood in the Dera. It would be a Gujjar woman who walks $2 \mathrm{kms}$ to and fro carrying the drinking water for the family and it is women again who lops the leaves of the trees for stall feeding the livestock and also to dry the grasses for the lean period.

It is the Gujjar women who lop the trees and the equation they share with the trees is like any living being. They believe that trees are active and lopping is a way of keeping trees alive. Kammo said, "Lopping is like reviving the life in the trees. We donot cut the tip of the trees or branches while lopping as that would be like beheading a person of his head or hands. Rather we cut the leaves as it's like shaving of the head which gives way to new and better hair." Gujjar women take care of the trees around them in the same manner as they do it for the new calf of buffalo. As Safoora puts it, "We welcome every calve into our family and take care of them as our family member. It's our duty to feed them. We do it with the trees around us so how can we harm the trees and cut those dead especially when the trees are giving life to our livestock. " Here, it implies that Gujjar women tend to their livestock and the trees around their Dera with the same love and care with which they tend to their own daughters and sons. Gujjar women seem to depend on natural resources to even interweave the dead aspects in their living aspects. Gujjar women share such intimate relationships with the trees around their Deras that they take personal care of each tree. Even a dead tree is turned into a milking bowl for serving milk to bhotiya dogs that Gujjar keeps for their safety against wild animals in the alpines. E.g. In the alpines, women make bowls out of the dead trees using their barks to serve milk for the dogs. 


\section{Coping through Normalizing and Acceptance}

Gujjar women are the one who foresee the necessity of keeping a 'back up' plan for the lean season. During the winter months, while the buffaloes are away grazing in the dense forests, women mostly cut the grass and dry it by putting in under the sun on the roof of their Deras. During the lean season as the summer season approaches, the grasses in the forest area dry up. So the dried up grass is used to feed the buffaloes for their survival. Husan Bano emphasizes that such fodder can be particularly useful during times of stress when other sources are likely to be under greater pressure and risk of drying in low production. This somewhere depicts the motherly care of Gujjar women who like any other mother literally implicates in making the hay when the sun shines for the livestock whom they treat like their daughters and sons.

Another Van Gujjar man who had to come down from the alpines for a medical urgency of his youngest son. While he was away, landslides blocked his way back and he was forced to stay back in the city. It was his wife, Safoora, who has been managing the family alone along with the livestock in the alpines. She woke up in the morning at 3:00a.m in the morning and begins to churn butter out of the milk for sale in the neighbouring local market. Then she sents her eldest son to milk the buffalo herd who had been away grazing. After cleaning and feeding her younger kids, she cleans the utensils and sheds meant for the buffalo kids. This way, she takes care of the hearth and herd as she says, "If the husband is out there taking care of a child, I understand I have to see to the responsibilities of the herd. We invest all our savings and take a lot of loan too for travelling to alpines and if we donot maximise on our stay here in alpine pastures then we shall get indebted beyond our survival. I am responsible for caring and counting the grazing animals as they come back from grazing and am the first person to notice the signals of problems in the livestock. After all, the livestock is also like our children"

\section{Coping in Social Matters}

Van Gujjar women take decisions alone in the social matters like marriage of their sons and daughters, concerning the extension of hospitality to guests and tending to child birth in a community household. Mason [8] mentions in his study that social context has indirect and direct effects on women's economic power. It is the first impression of being working machines that one gets of Gujjar females upon simple acquaintance but a deeper introspection leads one to a stronger images which move beyond the domestic household chores. As one of the Gujjari songs depicts: Your disloyalty has ruined my life totally and you have broken promises. Now I struggle to live but the struggle is with the one who is strong and not the one who is weak.

(This song was basically in Gujjari language but was translated by enumerator who was a Gujjar working as a field assistant with an NGO). This strongly implies that a Gujjar women is emotionally strong enough to recognize the losses in her life yet she considers herself beyond endurance levels of struggling against a weaker man who lacks credibility.

Gujjar women consider feeding of guests as an important activity. It is the hospitality levels extended by a Gujjar wife that reflects the respect of a Gujjar male. Its apparently that Gujjar male who upholds the respectability of the family on the face value but within closed quarters, it is the Gujjar women who have the autonomy of saying 'no' to entertaining the guests of her husband if in case she is offended by her husband. It is considered a big shame for a Gujjar male if his guests are not treated well, reflecting on his bonding and space within the household, henceforth, it is indirectly the women who upholds the man's respect and the Gujjar male reciprocates the same by taking good care of his wife.

Gujjar women form the core of most of the festivals and community events. It is through the rituals that Gujjar women creates their cultural space and establish themselves as independent individuals and social beings. Birth of a baby commands for the omnipresent security of older Gujjar females in almost all the rituals. Gujjars donot have any traditional dais of their own but the elder women of the community helps in delivery at home. Any signs of complications are immediately seeked for treatment by a government or private doctor at the nearest township which is normally at a distance of $20 \mathrm{kms}$. The first bath of a baby is performed in a broken earthen pot. This is a vivid reason because of which household materials like earthen pots are taken as symbolic representation of women's reproductive tendencies. A lady who has delivered a baby is confined to a corner of the main Chhapar(Central point of homestead) of Dera (homestead). This corner is transformed into a private resting space which is curtained with old sheets in order to provide the required warmth for the newly nursing mother. Gujjar women emphasize that this corner also provides the newly nursing mother and new born baby a security from the sudden exposure to the openness of the forest area. Fire is lit in the Chhapar to defend the mother and the child from evil spirits. During delivery, she is assisted by mid-wife or old ladies of the community. Immediately after delivery, a herbal concoction is fed to the mother to induce expulsion of placenta. This placenta is cut with a pair of scissors or any other sharp instrument and is buried in the ground near the house. The mother is given 'sonth' (dried ginger), a sweet nourishing condiment made from gur (Jaggery), dry fruits and certain herbs. The drink normally given to the mother for a fortnight or so is 'Achwani' which is water boiled with ajwain (Bishop's weed). She is fed with boiled rice in milk with plenty of ghee added to it. For duration of more than a fortnight, she is fed with milk twice or thrice a day so that the newly born baby remains well supplicated with nourished mother milk. It is the older women folk of the family who takes care of the newly born baby, relieving the newly nursing mother to regain back her strength. She is not allowed to attend to household chores till the time she does not feel strong enough to manage them. Haseena, a 23 year 
old, was pregnant with her first child while she was in transhumance to the alpines. She was given a complete loving attention on the way to the upward journey. Ample of spacing in the Dera was maintained based on the requirements of her resting durations. Upon reaching the alpines, she every year stayed along with her husband in a separate Dera but this year, her mother in law ensured that she shares the 'chullah'(kitchen) along with the extended family so that she gets enough rest and peace of mind. Her Dera duties were equally distributed between her sister in laws and mother in law. She gave birth to a baby boy and for this she was assisted by an older lady of the Gujjar clan who acts as a midwife for the Gujjar women in the alpines where the difficult terrain makes it impossible to move to a hospital. Soon after the birth, the old lady gave the newly born baby 'ghutti' (a concoction), a cleansing medicine for the stomach. The Ghutti is normally a concoction of boiled water along with sugar for the required strength for the baby and the 'sonth' for the cleansing. Normally in the foothills, 'gur' and 'batashas' ( condensed sugar cubes) are distributed but in the alpines, Gujjars staying near by are the extended family members so they come visiting the newly born baby. After washing and swaddling, the 'numberdar' (Head of the clan), Ulfa, whispered 'azan' ( call for offering prayer congregation, namaaz) thrice in his right ear and the 'kalima'(Quranic verses) in the left ear. The elderly midwife is offered a shirt cloth and a token of one rupee. All the relatives who gather are fed with sweet rice (boiled rice with homemade butter and sugar) and the naming ceremony 'aqiqa' takes place. It was quite intriguing as to how the 'aqiqa' could be performed without the sacrifice of a goat/ sheep. As per Islamic tradition, the 'aqiaqa' is performed with the sacrifice of a goat. I enquired one of the Gujjar women about it and was amazed at the in depth knowledge related to Islam they own. She answered, "Islam does not permit a person in debt to perform this ritual that is why we rarely go for sacrifices as we are indebted till our necks just to save the lives of our livestock so how can we sacrifice them. Can a mother sacrifice one child in lieu of safety of another child?"

It gets evident that women folk are central to all the decisions taken by the Van Panchayat (local informal governing body) in terms of any matter pertaining to elopements and marriage alliances. The menfolk come together for a meeting in which the older women of the community are also present. An intense discussion follows in the meeting but no decision is arrived at. The menfolk return back to their Deras to discuss the matters with their mothers, sisters, wives and daughters. The next day, every man presents the female perspective of their respective households and then a decision is taken pertaining to the issue.In this way, the community ensures that the women folk are given a platform to hear the otherwise unheard voices and they are involved indirectly in decision making process along with maintaining the unsaid rule of observance of purdah (veil) in social gatherings.

\section{Assurance for Moneylenders}

During fieldwork, there was not even a single household that borrowed money from banks or other financial institution. Since Gujjars are in the phenomenon of transhumance, they own no permanent place of residence and own no valuable assets to be used against security to procure loans. Owing to their uncertain social placement, small time money lenders exercise a lot of caution. Gujjars cannot apply for loan to banking institutions due to the fact that they do not own a permanent place of settlement and the wealth that they own is livestock which cannot be used as security to banking institutions. They do not own any immovable property like land or house owing to which they are unable to furnish a guarantee, to give surety or mortgage any valuable asset which is an essential condition to secure a loan or advance. Most of them therefore, raised loans from petty shopkeepers who supply their daily requirements of rations and animal feed on credit. It was also revealed from the study that since the livestock was in the name of Van Gujjar women so moneylenders rely on the credibility of Van Gujjar women while lending credit. Among the Van Gujjar women, majority of women could take credit on their own credibility. This meant the Van Gujjar women have the potentiality to fulfill the collateral and faith of informal debtors. Gujjar community is ubiquitously indebted. The problem of indebtedness is found in a virulent form and is endemic amongst the nomadic Gujjars. The credit is from the informal networks of Local Baniyas (moneylenders), milkmen and from other relatives. When the loan is credited to a family from rich kinsmen, it is owing to the friendly networking and socially amiable environment created amongst the two families by the respective females of the respective families. However, the loan within relatives is always paid back in cash.

The rate of interest that moneylenders charge is horrendously high. It is during these credit sessions that the oldest female of the household plays the most important role. Most of the times the informal loans by the moneylenders are credited to the families in which the female head maintain a good credibility in the community. The Females of such Gujjar household maintain a good rapport with these moneylenders and shopkeepers by paying back to them from time to time in kinds (Ghee and milk). The loans of moneylenders were normally repaid back on a yearly basis which is normally after coming back from the alpines. What they earn in lean winter months, they repay it back from the earnings they make during summer seasons in the pastures. It is very rare that any Gujjar yields to distress selling of his Buffalo and for this purpose, they have begun to breed small ruminants like sheeps. Shammi, a Van Gujjar emphasizes, "our men have an attitude of being chaudhris (landowners). They are never there during the daytime, grazing the buffaloes in the jungle (forest), so it is the females who are left behind to entertain the guests in the Deras. As moneylenders come to seek for their loan then we prepare tea and the oldest woman of the household, sits around the central fire place, to negotiate with them. It is our assurance of paying back their debt on time and we ensure we save on money to repay back to moneylenders." 


\section{Conclusions}

The research aimed to present perspectives of women from Van Gujjar community. This Paper is based on a mixed research in which the quantitative aspect aimed at identifying the factors and levels of women empowerment before and after sedentarization through a Women empowerment Index. Qualitative research aimed to explore perspectives of young women from Gujjar community in terms of patterns of coping in their life. Narratives of women presented a sense of collectivism and identification with issues and concerns of other Gujjars in terms of an identity of victimhood and a sense of being marginalized and socially excluded. Following patterns of coping emerged from narratives: Use of existing resources, Women as Livestock owners and managers, Women as Leaders in Migration, Work Participation and status of women, Women as Builders of Asset base, Gujjar women- the Natural resource managers, Coping through normalizing and acceptance, Coping in social matters, Assurance for moneylenders. The emphasis of the research was not on generalizing the findings but on presenting voices of some Van Gujjar women from different backgrounds. Further research will be useful on the important questions that have emerged. It is important that we understand people's vulnerabilities and coping strategies instead of highlighting their resistance strategies. At the same time, just because people cope and adapt, it does not imply that we should not focus on creation of a sustainable environment for people. Diverse stakeholders need to continue to work towards creating sustainable livelihood and respectable civil rights for everyone. This involves questioning the 'national' narrative that, according to Safoora, "If government does not think about us, then at least we can think about us. Now resources are getting limited so our options of sustenance on pastoralism are also getting limited. We need a good synthesis of sedentarization and pastoralism."

With the changing situations, it gets imperative for Van Gujjars to join the semi-nomadic pastoralists of the world, by combining a settled existence with its possibilities of respectable civil rights and diversification with transhumance for the animals. Most of the Van Gujjars have begun to resort to adaptations in migration with adjustments on the migratory routes and culture based sustenance strategy related to reduced pastures by sending their buffaloes to the alpine pastures along with their relatives. The migration process entails severe harassments and struggle and they are ready to settle down. However, in a discussion about semi-nomadism, Kammo, one of the women said: 'That would be much better for our future generations. The condition of only sedentarized Van Gujjars at Resettlement colonies shows that we should than not just opt for sedentarization in settlement colonies. A synthesis of both is what we seek for!!

\section{REFERENCES}

[1] Guha R. Scientific Forestry and Social Change in Uttarakhand. India: Economic and Political weekly; 1985.

[2] Maikhuri R.K, Nautiyal S, Rao K.S, Saxena K.G, Conservation Policy- people conflict: A case study from Nanda Devi Biosphere Reserve, In Forest policy and Economics, 2001.

[3] Nusrat R, Marginalisation of Himalayan pastoralists of Uttarakhand and exclusion from their traditional habitat- A case study of Van Gujjars in India, International Journal of Human Development and Sustainability, Volume 4, Number 1: Spring 2011, ISSN: 0974-3529,ISBN: 978-1-61233-519-3, 2011.

[4] Gooch Pernille, Nomadic Muslim Gujjars-a pastoral tribe in north India; a case for survival, RLEK, Dehradun, 1994.

[5] Flintan, F. "Sharing of Past Experiences" in Gender and Pastoralism: Volume I: Rangeland and Resource Management in Ethiopia. A. Ridgewell, G. Mamo and F. Flintan, Addis Ababa: SOS Sahel. Internet:http://www.sahel. org.uk/publications.html, 2007a

[6] Nusrat R, Custodians of culture sustain forest biodiversity through participatory planning and Management in Himalayas, edited chapter in Sustainable Forestry, LG Publishers and Distributors, New Delhi, 2013

[7] Edgaonkar, A., Utilization of major fodder tree species with respect to the food habits of domestic buffaloes in Rajaji National Park, India. Abstracts: Ninth Annual Research Seminar 25th-26th September, 1995.

[8] Mason, Karen, The Status of Women: Conceptual and Methodological Issues in Demographic Studies, Sociological Forum, 1986. 1(2):284-300. 